\title{
COUPLED TIDES, STORM SURGE AND WAVES UNDER VARYING ICE COVERGAGES ALONG ALASKA'S BERING AND CHUKCHI COASTS
}

\author{
Joannes J. Westerink, University of Notre Dame, jjw@nd.edu \\ Brian Joyce, University of Notre Dame, bjoyce@nd.edu \\ Robert Grumbine, NOAA NWS/NCEP Environmental Modeling Center, robert.grumbine@noaa.gov \\ Andre van der Westhuysen, NOAA NWS/NCEP Environmental Modeling Center, andre.vanderwesthuysen@noaa.gov \\ Jesse Feyen, NOAA Great Lakes Environmental Research Laboratory, jesse.feyen@noaa.gov \\ William J. Pringle, University of Notre Dame, william.j.pringle.4@nd.edu \\ Dam Wirasaet, University of Notre Dame, dwirasae@nd.edu
}

\begin{abstract}
INTRODUCTION
The western coastline of Alaska spans over a diverse topography ranging from low lying tundra to sharp volcanic relief. Included in this range are areas highly susceptible to powerful storms which cause coastal flooding, erosion and have many other negative effects on the environment and commercial efforts in the region. To better understand the multi-scale and interactive physics of the deep ocean, continental shelf, near shore, and coast, a large unstructured grid hydrodynamic model has being developed using the finite element, free surface circulation code ADCIRC coupled to the WAVEWATCH III third generation non-phase resolving wave code. This is a high resolution, accurate, and robust computational model of Alaska's coastal environment capable of simulating tides, storm surges, and storm waves as well as their coupling.
\end{abstract}

\section{TIDES AND STORM SURGE}

Hydrodynamically, the tides in this region are very complex with a large number of amphidromic points and a very large tidal range. We do consider ice drag on the currents although we do assume that ice is stationary although ice coverage evolves in time. Ice coverage is constructed based on available satellite products. The model's tidal solution has been validated at 121 shelf based and nearshore stations. The model has been successfully validated for summer storms where ice coverage is not present in most of the domain. Sea ice has been incorporated through a parameterized wind drag coefficient which modifies the air sea momentum transfer in the presence of ice coverage. Three large winter storms with distinctly different ice coverages were chosen to exhibit the variable effect of sea ice on the resulting storm surge. Performance is generally good. Under forming coastal ice coverage, an increase in water levels due to ice is seen in coastal areas, but overall water levels are under predicted. Under dense pack ice, an increase in momentum transfer in the marginal sea ice at the shelf break leads to increased sea levels across the Bering Sea despite an expected decrease in water levels. Under a highly variable ice field, results are much more mixed, as the underlying assumptions about ice movement used to derive the drag parameterization may break down. To improve model performance with respect to coastal water levels, it would be desirable to include the contribution of wave radiation stresses induced in coastal areas and under ice cover, as well as a description of sea ice movement, as it controls the air-sea-ice momentum transfer.
WAVES AND HYDRODYNAMIC COUPLING

Wavewatch III is coupled to ADCIRC through the Earth System Modelling Framework (ESMF). Wavewatch III as implemented into our model incorporates ice physics developed through an Office of Naval Research funded Directed Research Initiative, allowing storm wave guidance in the nearshore and allowing for momentum to be transferred from the wind waves into the surge. Particular attention is given to the wave radiation stresses generated across the marginal ice zones, both for nearshore ice and marginal sea ice at the edge of the Bering shelf and compared with the general enhancement of wind air-sea drag across these interfaces.

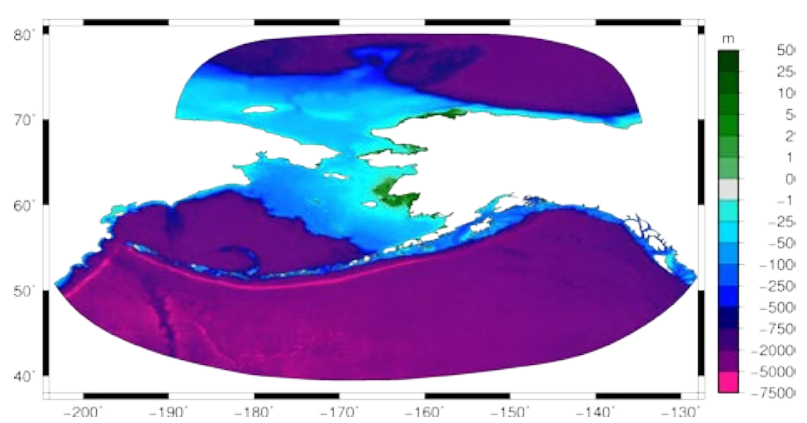

Figure 1 - Domain definition.

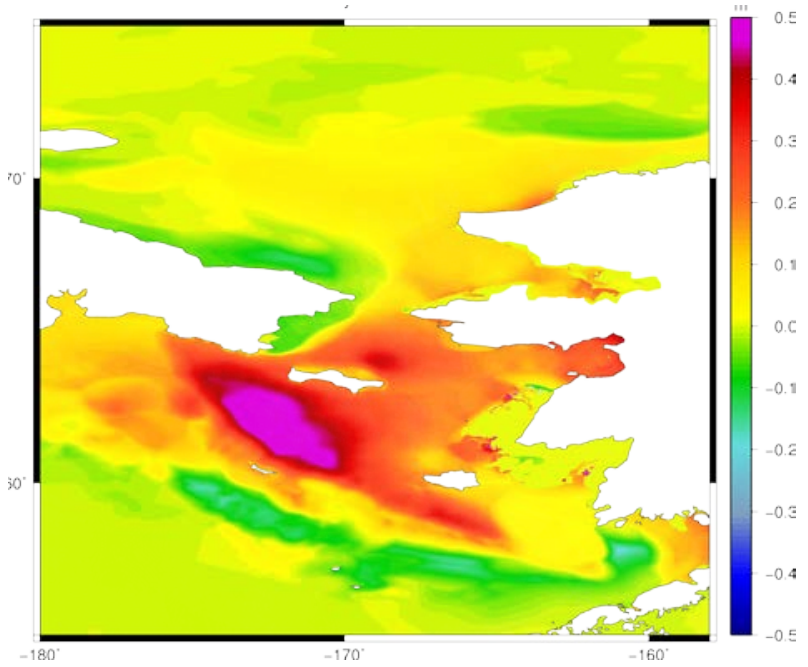

Figure 2 - Enhancement of water level due to momentum transfer across the marginal ice zones in February 2011. 